\title{
Comportamento morfológico e sedimentar da praia de Itaipuaçú (Maricá, RJ) nas últimas três décadas
}

\author{
André Luiz, Carvalho da Silva ${ }^{1}$, Maria Augusta Martins da Silva ${ }^{2}$ \& Carla Luiza dos Santos ${ }^{3}$
}

\begin{abstract}
Resumo O principal objetivo do presente estudo, realizado na praia de Itaipuaçú (município de Maricá, estado do Rio de Janeiro), é a compreensão do comportamento morfológico e sedimentar desse litoral nas últimas três décadas. A metodologia consistiu de uma série de perfis topográficos de praia contínuos utilizando-se o método proposto por Emery (1961) obtidos sazonalmente ao longo de 8 anos, associada com análise granulométrica de 40 amostras coletadas na superfície da praia. Os dados foram então comparados com trabalho publicado na década de 70. Os resultados indicam que a parte oeste do arco de praia é a mais dinâmica como conseqüência da intensa energia local das ondas de tempestades de sul e sudoeste. A morfologia e os sedimentos indicam que esta dinâmica diminui em direção a leste. Os sedimentos predominantes são de areias muito grossas, entretanto a granulometria diminui em direção a leste, onde areia grossa de melhor grau de selecionamento é mais característica nos sedimentos da praia. Comparação entre perfis topográficos realizados ao longo de 8 anos com perfis coletados na década de 70 mostra que, apesar da grande dinâmica apresentada pela praia e, em particular, o extremo oeste, a praia tem mantido a mesma morfologia, e o mais importante, a mesma largura, o que não é um indicador de erosão da praia até o presente momento.
\end{abstract}

Palavras-chave: praia, Itaipuaçú, morfologia, sedimentologia, erosão.

\begin{abstract}
Morphological and sedimentary behaviour at Itaipuçú beach (Maricá, RJ) along the last there decades. The main objective of the present study, carried out in the Itaipuaçú beach (Maricá, Rio de Janeiro state), is to understand the morphological and sedimentary behaviour of this coastline along the last three decades. The methodology consisted of a continuous series of beach profiles employing Emery's method (1961) obtained seasonally along 8 years, associated with grain size analysis of 40 samples collected from the beach surface. The data was then compared to work published in the 70's. The results indicate that the western part of the beach arc is the most dynamic as consequence of local intense energy of S-SW storm waves. Morphology and sediment trends indicate that this dynamics decrease towards the east. The most abundant sediment is very coarse sand, however grain size decreases towards the east where a better sorted coarse sand is the most characteristic beach sediment. Comparison between this 8-year long series of profiles to profiles collected in the 70's shows that, despite the great dynamics of the entire beach and in particular, the western extreme, the beach has maintained the same morphology, more important, its width, which is not an indication of beach erosion at the present time.
\end{abstract}

Keywords: beach, Itaipuaçú, morphology, sedimentology, erosion.

INTRODUÇÃOO O presente estudo objetiva contribuir para um melhor entendimento do comportamento morfológico e sedimentar da praia de Itaipuaçú, localizada no município de Maricá (RJ) (Fig. 1). Este trecho do litoral está situado a cerca de $13 \mathrm{~km}$ a leste da entrada da Baía de Guanabara e possui uma extensão de aproximadamente $10 \mathrm{~km}$ de orientação $\mathrm{E}$ - W, sendo limitada à oeste pela Pedra do Elefante (parte da serra da Tiririca) e à leste pelo Pontal de Itaipuaçú. Trata-se de um trecho do litoral que vem experimentando um rápido processo de urbanização nas últimas décadas, principalmente no setor oeste de Itaipuaçú, na área próxima da serra da Tiririca, limite com a cidade de Niterói (RJ). Sendo assim, em meio a crescente urbanização dessas áreas, observa-se uma série de problemas, sobretudo por se tratar de uma praia muito dinâmica. Tais transformações consistem na destruição de avenida, postes, muros, calçadões, quiosques, etc.

O litoral de Itaipuaçú (Fig. 2) é conhecido pela característica rara do sedimento que compõe sua praia: areias, grânulos e seixos muito bem arredondados formados em grande parte por quartzo puro. Outra característica marcante dessa praia é a alta energia das ondas incidentes que ocasionam fortes ondas na arrebentação provenientes principalmente do quadrante sudeste associada às condições de tempo bom e, sul e sudoeste, quando da ocorrência de ressacas causadas pela passagem ocasional de frentes frias. Apresentando um perfil refletivo típico, a parte oeste dos $10 \mathrm{~km}$ de praia vem mostrando amplas variações morfodinâmicas no

1- Programa de Pós-graduação em Geologia e Geofísica Marinha, Departamento de Geologia, Universidade Federal Fluminense/UFF, Niterói (RJ), Brasil. E-mail: andrelcsilva@igeo.uff.br

2- Departamento de Geologia, UFF, Niterói (RJ), Brasil. E-mail: augusta@igeo.uff.br

3- Programa de Pós-graduação do Departamento de Geologia da UFF, Niterói (RJ), Brasil. 


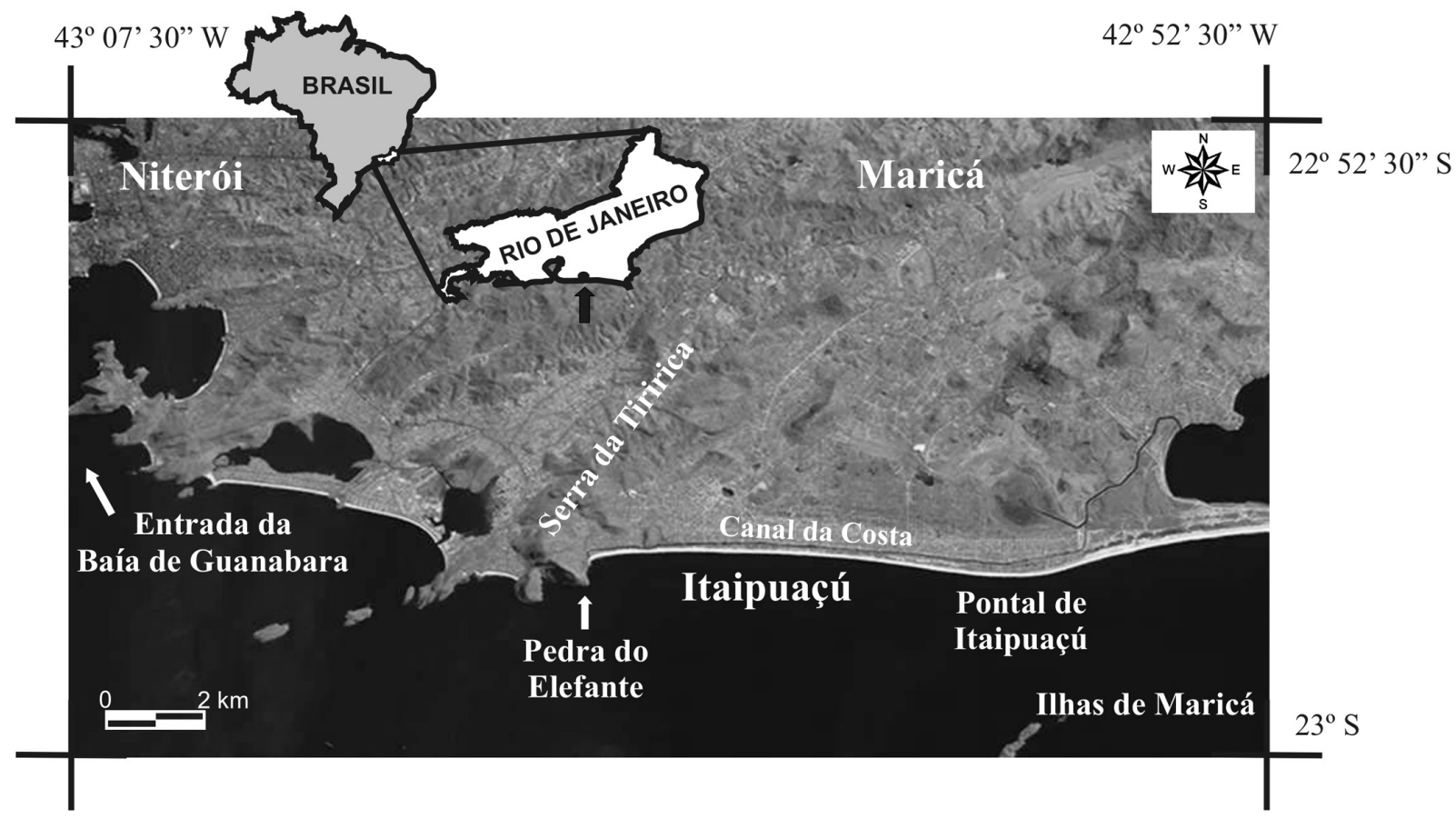

Figura 1 - Localização da área de estudo. Imagem do satélite Landsat. Carta: SF-23Z-B-IV-4-SE (site: www.cdbrasil.cnpm.embrapa.br).

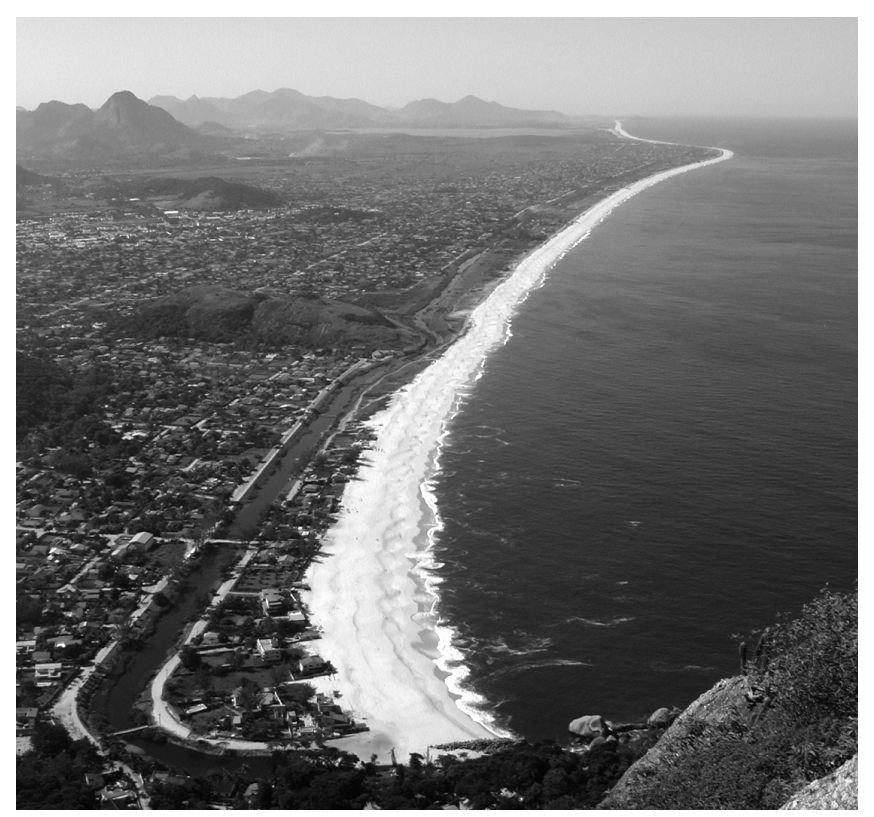

Figura 2 - Praia de Itaipuaçú (município de Maricá, RJ), vista para leste a partir da Pedra do Elefante na Serra da Tiririca. 14 de junho de 2005.

intervalo de tempo de cerca de 8 anos de levantamentos de campo (Santos \& Silva 2000, Silva et al. 2006, Silva 2006). Do mesmo modo, a crista da restinga, vem apresentando inúmeras alterações no período indicado: ondas de ressaca formam e desenvolvem leques de arrombamento, removem dunas e vegetação. Tais fenômenos promovem o recuo ou retrogradação da barreira e a praia hoje já se posiciona em locais anteriormente (década de 90) ocupados pela vegetação de restinga (Silva et al. 2005, Silva 2006). Em conseqüência disso, o impacto nas construções é enorme.

O entendimento da dinâmica do litoral de Itaipuaçú visa subsidiar políticas voltadas para o planejamento urbano, para o gerenciamento costeiro e, acima de tudo, para a conscientização no sentido de que qualquer forma de intervenção, quando esta for inevitável, deve respeitar as características e os limites deste ambiente, que é essencialmente dinâmico.

MÉTODOS DE TRABALHO Com o propósito de melhor entender e caracterizar os fenômenos que estão ocorrendo nessa área, dividiu-se a praia em cinco locais de monitoramento (Tab. 1). A partir de então, empregou-se a seguinte metodologia: (1) realização de perfis topográficos de praia nos verões e invernos, ao longo de 8 anos, utilizando-se o método das balizas proposto por Emery (1961), que consiste na realização de perfis perpendiculares à linha de praia, começando no limite interno da praia, indo até o nível médio das ondas, para registrar a topografia da praia no momento da observação. A coleta de dados foi sempre realizada nas mesmas condições de maré (maré baixa de quadratura); (2) análise granulométrica de 40 amostras de sedimentos superficiais coletadas entre o verão de 2004 e o verão de 2006, e a comparação dos resultados obtidos com os apresentados por Santos \& Silva (2000); e (3) comparação dos resultados obtidos aos levantamentos efetuados na década de 70 (Muehe 1975).

Os locais de coleta das amostras de sedimentos superficiais correspondem aos trechos onde foram realizados os perfis de praia, sendo que, em cada uma des- 
Tabela 1 - Coordenadas UTM do ponto inicial dos perfis topográficos de praia.

\begin{tabular}{c|c|c|c|c}
\hline \multicolumn{5}{c}{ Praia de Itaipuaçú } \\
\hline $\begin{array}{c}\text { Extremo oeste junto à } \\
\text { pousada do Recanto. }\end{array}$ & $\begin{array}{c}\text { Centro-oeste alinhado } \\
\text { com a antena de } \\
\text { telefonia. }\end{array}$ & $\begin{array}{c}\text { Meio do arco de praia } \\
\text { em frente à avenida 1. }\end{array}$ & $\begin{array}{c}\text { Extremo leste em } \\
\text { frente ao bar Biroska } \\
\text { dos Pescadores. }\end{array}$ & $\begin{array}{c}\text { Junto ao pontal de } \\
\text { Itaipuaçú. }\end{array}$ \\
\hline N-7458399 & N-7458447 & N-7458422 & N-7458000 & N-7458065 \\
\hline E-703821 & E-704525 & E-707165 & E-711261 & E-714900 \\
\hline
\end{tabular}

sas áreas, a amostragem foi feita na área do pós-praia (região de supramaré - parte emersa da praia) e frente de praia (região de intermaré - parte da praia sujeita ao alcance diário das ondas), empregando-se a terminologia de praia proposta por Silva et al. (1999). A coleta da amostra foi realizada nos primeiros centímetros de sedimentos superficiais, abrangendo uma área representativa do perfil estudado.

$\mathrm{Na}$ análise granulométrica das amostras, realizada no laboratório de sedimentologia do Departamento de Geologia do Instituto de Geociências da UFF, utilizou-se uma "torre" de peneiras sobrepostas com abertura em milímetros de 4.00, 2.83, 2.00, 1.00, 0.500, $0.250,0.125$ e 0.062 . Os resultados da análise granulométrica permitem a classificação dos sedimentos baseando-se na classificação proposta por Wentworth (1922). Os resultados das análises granulométricas foram processados no Microsoft Excel, que possibilitou a confecção dos histogramas utilizados para representar graficamente os dados granulométricos.

Por ocasião da realização dos perfis foram observadas ainda algumas condições de mar, tais como: altura da onda na arrebentação, tipo de arrebentação, direção de chegada das ondas e período médio das ondas (sempre estimado por 2 ou 3 pessoas).

Os dados referentes aos perfis topográficos de praia coletados foram processados no software Grapher. A geração de perfis de praia individuais permite a caracterização morfológica da praia por ocasião da coleta de dados e a sobreposição dos mesmos permite a observação das variações morfológicas da praia através dos perfis novos e pretéritos. Os resultados podem ser comparados aos perfis pretéritos permitindo com isso uma compreensão das variações ao longo de um intervalo de tempo maior.

\section{RESULTADOS E DISCUSSÕES}

Condições de mar As observações das condições de mar (direção da onda, forma de arrebentação, altura e período médio das ondas incidentes junto à praia) permitiram uma caracterização do estado de mar por ocasião dos levantamentos de campo.

A praia estudada está sujeita à ação de ondas provenientes de SE, S e SW (Fig. 3). Os resultados dessas observações (Tab. 2), indicam que a incidência de ondas provenientes de SE associadas ao tempo bom são predominantes, tanto no verão quanto no inverno. Es-
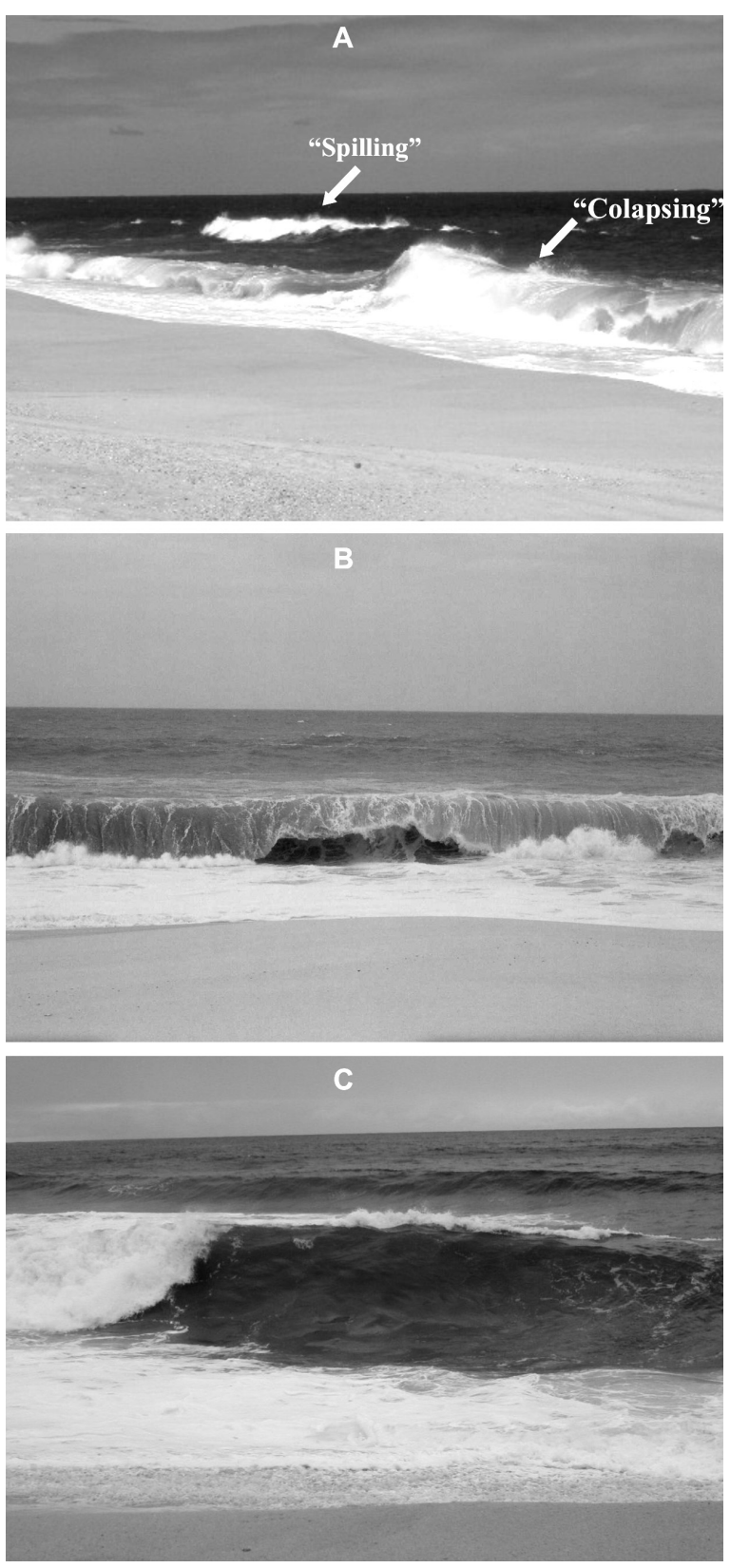

Figura 3 - Condições de mar características: (A) Incidência de ondas provenientes de sudeste em Itaipuaçú com arrebentação do tipo "colapsing" $e$ "spilling" (outubro de 2004), (B) de sul com arrebentação do tipo "plunging" (setembro de 2004) $e$ (C) de sudoeste com arrebentação do tipo "spilling" (julho de 2005). 
tas ondas, durante os trabalhos de campo, apresentaram altura média entre 0,20 e 1,00 m, aproximadamente, chegando a atingir uma média de $1,50 \mathrm{~m}$ no inverno de 2004. O período médio destas ondas variou entre 7,5 (verão-2006) e 13,6 segundos (inverno-2004), sendo que, em alguns monitoramentos foi possível perceber dois padrões distintos de períodos de ondas. A forma de arrebentação das ondas de SE varia significativamente, predominando o tipo "colapsing" $(\mathrm{C})$, seguido por "spilling" (Sp) e "plunging" (P), além de "surging" (Su) em menor proporção (Fig. 3A). As ondas associadas a tempestades e, conseqüentemente as de maior energia, são de S e, principalmente, de SW. Estas ondas apresentaram altura média entre 0,40 e $1,10 \mathrm{~m}$, chegando a atingir $3 \mathrm{~m}$ de altura durante ressacas. O período médio variou entre 8,4 (inverno-2004) e 11,8 segundos (inverno-2005). A forma de arrebentação das ondas de S e SW são predominantemente do tipo "plunging" (P),

Tabela 2 - Dados relativos às condições de mar observadas na praia de Itaipuaçú por ocasião dos trabalhos de campo: direção da frente de ondas e forma de arrebentação, estado de mar, altura (H) e periodo (T) das ondas incidentes junto à praia.

Praia de Itaipuaçú

\begin{tabular}{|c|c|c|c|c|c|c|}
\hline & & Perfil A & Perfil B & Perfil C & Perfil D & Perfil E \\
\hline \multirow{5}{*}{ Verão 2004} & Direção & SE & SE & SE & SE & SE \\
\hline & Arrebent. & $\mathrm{C}, \mathrm{P}$ & $\mathrm{C}, \mathrm{P}$ & $\mathrm{P}, \mathrm{C}$ & $\mathrm{C}, \mathrm{P}$ & $\mathrm{P}, \mathrm{C}$ \\
\hline & Mar & calmo & calmo & calmo & calmo & Calmo \\
\hline & Altura $(\mathrm{H})$ & $0,71 \mathrm{~m}$ & $0,48 \mathrm{~m}$ & $0,36 \mathrm{~m}$ & $0,34 \mathrm{~m}$ & $0,98 \mathrm{~m}$ \\
\hline & Período (T) & $10,1 \mathrm{~s}$ & $12,6 \mathrm{~s}$ & $10,0 \mathrm{~s}$ & $11,7 \mathrm{~s}$ & $09,5 \mathrm{~s}$ \\
\hline \multirow{5}{*}{ Inverno 2004} & Direção & SE & SE & $\mathrm{SE}$ & $\mathrm{S}, \mathrm{SW}$ & SE, SW \\
\hline & Arrebent. & $\mathrm{C}, \mathrm{Su}$ & $\mathrm{C}, \mathrm{Su}$ & $\mathrm{Sp}$ & $\mathrm{P}$ & $\mathrm{P}, \mathrm{C}, \mathrm{Sp}$ \\
\hline & Mar & calmo & calmo & agitado & calmo & Calmo \\
\hline & Altura $(\mathrm{H})$ & $0,45 \mathrm{~m}$ & $0,56 \mathrm{~m}$ & $1,44 \mathrm{~m}$ & $0,82 \mathrm{~m}$ & $0,78 \mathrm{~m}$ \\
\hline & Período (T) & $12,5 \mathrm{~s}$ & $10,8 \mathrm{~s}$ & $13,6 \mathrm{~s}$ & $08,4 \mathrm{~s}$ & 09,2 \\
\hline \multirow{5}{*}{ Verão 2005} & Direção & SW, S & S & S & S & S \\
\hline & Arrebent. & $\mathrm{P}, \mathrm{C}$ & $\mathrm{C}, \mathrm{P}$ & $\mathrm{P}, \mathrm{C}$ & $\mathrm{P}, \mathrm{C}$ & $\mathrm{P}, \mathrm{C}$ \\
\hline & Mar & calmo & calmo & moderado & moderado & moderado \\
\hline & Altura (H) & $0,45 \mathrm{~m}$ & $0,37 \mathrm{~m}$ & $0,97 \mathrm{~m}$ & $0,84 \mathrm{~m}$ & $0,88 \mathrm{~m}$ \\
\hline & Período (T) & $08,8 \mathrm{~s}$ & $09,7 \mathrm{~s}$ & $09,7 \mathrm{~s}$ & $10,2 \mathrm{~s}$ & $09,0 \mathrm{~s}$ \\
\hline \multirow{5}{*}{ Inverno 2005} & Direção & SW, S, SE & $\mathrm{S}, \mathrm{SW}$ & $\mathrm{SE}$ & $\mathrm{SE}$ & $\mathrm{SE}$ \\
\hline & Arrebent. & Sp, C, P & Sp, P, C & $\mathrm{C}, \mathrm{P}$ & $\mathrm{C}, \mathrm{P}$ & $\mathrm{P}, \mathrm{C}$ \\
\hline & Mar & agitado & agitado & calmo & calmo & moderado \\
\hline & Altura $(\mathrm{H})$ & $1,15 \mathrm{~m}$ & $1,13 \mathrm{~m}$ & $0,91 \mathrm{~m}$ & $0,59 \mathrm{~m}$ & $1,06 \mathrm{~m}$ \\
\hline & Período (T) & $11,8 \mathrm{~s}$ & $10,9 \mathrm{~s}$ & $09,7 \mathrm{~s}$ & $08,8 \mathrm{~s}$ & $10,2 \mathrm{~s}$ \\
\hline \multirow{5}{*}{ Verão 2006} & Direção & SE & SE & $\mathrm{SE}$ & SE, S & SE, S \\
\hline & Arrebent. & $\mathrm{Sp}, \mathrm{Su}$ & $\mathrm{Sp}, \mathrm{Su}$ & $\mathrm{Sp}$ & $\mathrm{Su}, \mathrm{Sp}$ & $\mathrm{C}, \mathrm{Su}$ \\
\hline & Mar & calmo & calmo & calmo & calmo & moderado \\
\hline & Altura $(\mathrm{H})$ & $0,20 \mathrm{~m}$ & $0,22 \mathrm{~m}$ & $0,39 \mathrm{~m}$ & $0,38 \mathrm{~m}$ & $0,35 \mathrm{~m}$ \\
\hline & Período (T) & $10,0 \mathrm{~s}$ & $08,5 \mathrm{~s}$ & $07,5 \mathrm{~s}$ & $10,5 \mathrm{~s}$ & $07,3 \mathrm{~s}$ \\
\hline
\end{tabular}


seguida por colapsing (C) e spilling (Sp) (Fig. 3B e C).

A arrebentação das ondas ocorre praticamente junto à linha d'água, onde comumente se observa um canal proeminente paralelo à praia. Verificou-se ainda, a quase total inexistência de "zona de surf" nesta praia, exceto junto ao extremo oeste onde pode ocorrer uma discreta "zona de surf". Correntes de deriva litorânea nesta praia parecem predominar em direção a oeste, em resposta à obliqüidade na incidência de ondas provenientes de sudeste. No entanto, a incidência ocasional de ondas provenientes de mais de uma direção (SE e SW, por exemplo) pode contribuir para a geração de correntes tanto para oeste quanto para leste ao longo da praia. Esse comportamento foi constatado no inverno de 2004, com a corrente de deriva litorânea para oeste nos locais dos perfis A e B e para leste no perfil D.

Perfis topográficos de praia A praia de Itaipuaçú, em todos os monitoramentos realizados entre $1998 \mathrm{e}$ 2006 (verão e inverno) apresentou uma dinâmica diferenciada ao longo dos seus 10 quilômetros de extensão: maior dinâmica e maior variabilidade dos perfis topográficos no setor oeste (perfil B e, principalmente A) e perfis topográficos com pouca variação na largura e na morfologia no meio do arco de praia (perfil C) e no extremo leste (perfis D e E) (Figs. 4 e 5).

As maiores variações na largura da praia foram observadas na área do perfil $\mathrm{A}$, que variou entre cerca de 100 metros no verão de 1999 e 35 metros no inverno de 2002 (Figs. 4 e 5). Foi também no setor oeste da praia, que se verificou perfis com ângulo de inclinação acentuado, sobretudo na frente de praia, que diminuem de inclinação em direção à leste (Tab. 3). Os perfis da frente de praia do inverno de 2002 e 2005 neste trecho apresentaram-se, respectivamente, com inclinação de $35^{\circ}$ e $40^{\circ}$ (Fig. 6). No setor leste da praia (perfis D e E) é possível constatar uma diminuição significativa nos ângulos de inclinação da frente de praia, que variaram entre $15^{\circ}$ (verão de 2003 no perfil D) e $23^{\circ}$ (verão de 2004 no perfil D e de 2006 no perfil E) (Tab. 3).

Apesar da dinâmica elevada ao longo de toda a sua extensão, no meio do arco praial e na extremidade leste a praia apresentou-se praticamente com a mesma largura e com poucas variações na morfologia (Figs. $4 \mathrm{e}$ 5). No extremo leste, por exemplo, o perfil E apresenta larguras que variam de $63,5 \mathrm{~m}$ (verão de 2005) a 75 metros (inverno de 2005) (Figs. 4 e 5).

O comportamento caracterizado pelo estreitamento da praia no inverno, em resposta a ação de ondas de ressacas, assim como o seu alargamento no verão subseqüente, restringe-se apenas ao extremo oeste da praia (perfil A), onde este padrão clássico foi constatado em todos os monitoramentos observados ao longo de 8 anos (Fig. 4). No meio do arco de praia e, principalmente, no setor leste (perfis D e E), os perfis são mais estáveis e, em alguns casos, refletem um ligeiro aumento na largura da praia no inverno (Fig. 4 e 7).

Os perfis topográficos de praia coletados entre os anos de 1998 a 2006, quando comparados com os dados de perfis coletados na década de 70 (Muehe 1975) no meio do arco de praia em Itaipuaçú (Fig. 8), permitem a compreensão do comportamento dessa parte do litoral num intervalo de tempo de pouco mais de 3 décadas: a largura da praia neste trecho tem sido praticamente a mesma, ao longo de três décadas; a variação observada pode ser resultado da dinâmica sazonal característica do próprio ambiente, não tendendo ao efetivo alargamento nem estreitamento. Os perfis topográficos coletados por Muehe (1975) foram realizados diariamente, ao longo de 14 dias, no inverno de 1973 e mostram que a largura da praia variou de pouco mais de 40 a 65 metros aproximadamente. Perfis coletados na primavera de 1998 e verão de 1999 apresentaram largura de 33 m e 52,5 m, respectivamente (Santos \& Silva 2000); na primavera de 2001 e no verão de 2003 , respectivamente, a praia apresentou $61,5 \mathrm{~m}$ e $71 \mathrm{~m}$ ); entre 2004 e 2006 os perfis apresentaram 69 metros (verão-2004), 55,5 metros (inverno-2004), 63 metros (verão-2005), 70,5 metros (inverno-2005) e 68 metros (verão-2006) (Fig. 4). Desta forma, a análise da variação na largura da praia a partir de dados de perfis coletados ao longo dessas três décadas, permite afirmar que o meio do arco praial vem apresentando um comportamento morfodinâmico relativamente estável.

Perfis de praia e antepraia ("shoreface") realizados no meio do arco praial em Itaipuaçú (Muehe \& Corrêa 1989) apresentam uma declividade acentuada para o perfil submerso, sobretudo na região da "shoreface" superior que apresenta alta concavidade em lâmina d'água de até 10 metros (Fig. 9). Perfis com esta morfologia são característicos de costas com praias erosivas, como ocorre, por exemplo, em trechos da costa Atlântica dos Estados Unidos (Swift 1975 apud Muehe 1984). Tal declividade é indicador de um comportamento erosivo desta área submersa.

A análise integrada de dados coletados entre 1998 e 2006 permitiu verificar que a acentuada inclinação apresentada pela frente de praia (Tab. 3), assim como o maior dinamismo no extremo oeste da praia (perfis A e B) (Fig. 4 e 5), pode ser o produto da ação combinada: (1) da dinâmica mais intensa deste trecho devido à ação das ondas de tempestades, predominantes de sul e sudoeste; somado à influência do costão rochoso na aproximação de ondas, que neste caso pode estar ocasionando a convergência das ondas incidentes neste trecho, intensificando a energia das mesmas através dos processos de refração e difração, o que conseqüentemente, aumenta a capacidade de remobilizar sedimentos; (2) da influência da corrente de deriva litorânea no transporte de sedimentos ao longo da praia em direção a oeste. A formação de tais correntes é condicionada, sobretudo pela predominância da incidência de ondas de sudeste, comuns nesta área, principalmente no verão (Fig. 7).

Análise granulométrica dos sedimentos de praia A análise granulométrica das 40 amostras superficiais de sedimentos de praia permitiu constatar o predomínio da fração arenosa ao longo dos cerca de 10 quilômetros de praia, apesar da quantidade considerável de cascalho, sobretudo nas proximidades dos perfis A e B. Os resultados 


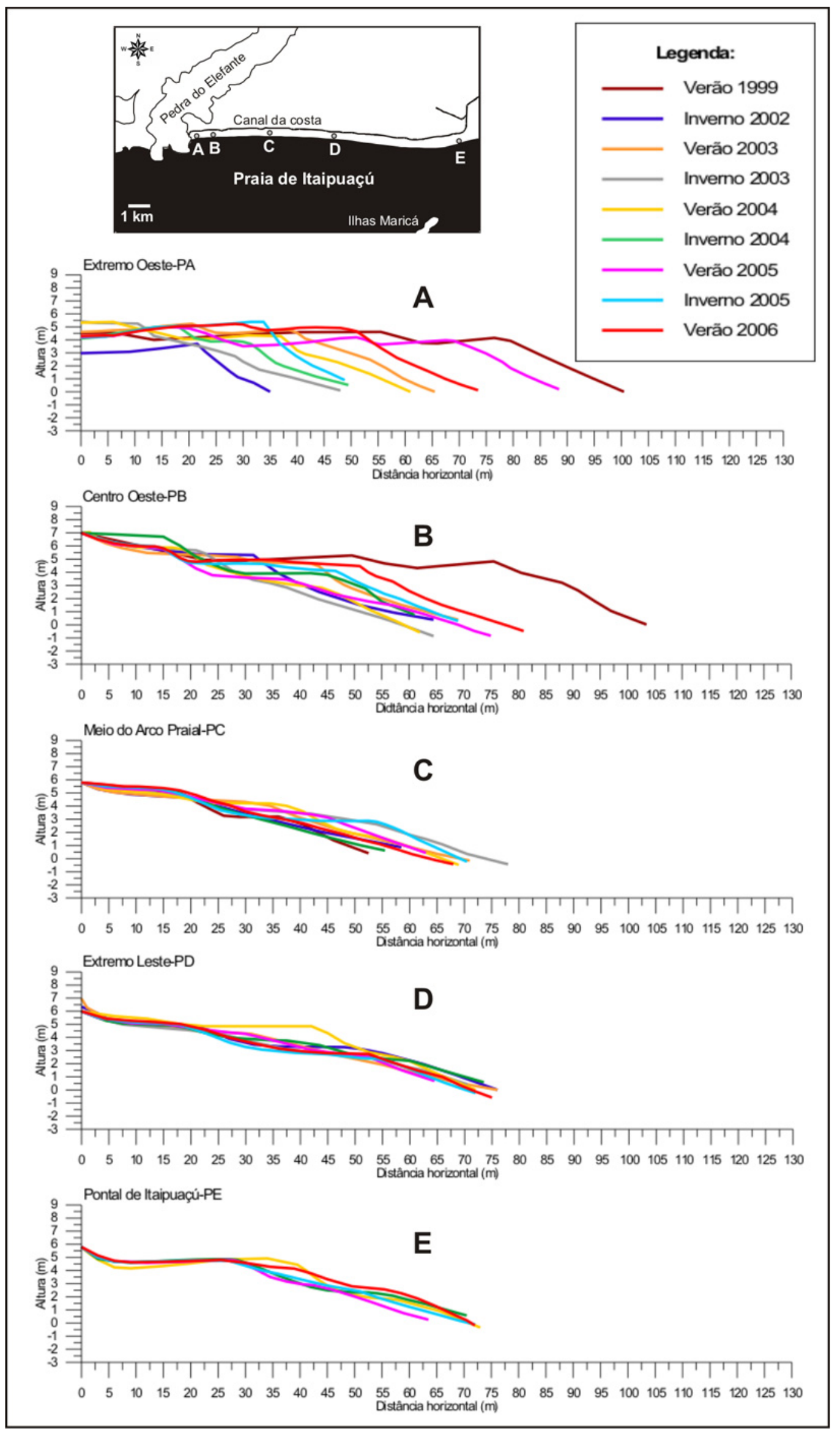

Figura 4 - Perfis topográficos de praia em Itaipuaçú levantados entre 1999 e 2006. Imagem de Magalhães, M. (Nautilus Navegator), Itaipuaçú - 2004. 

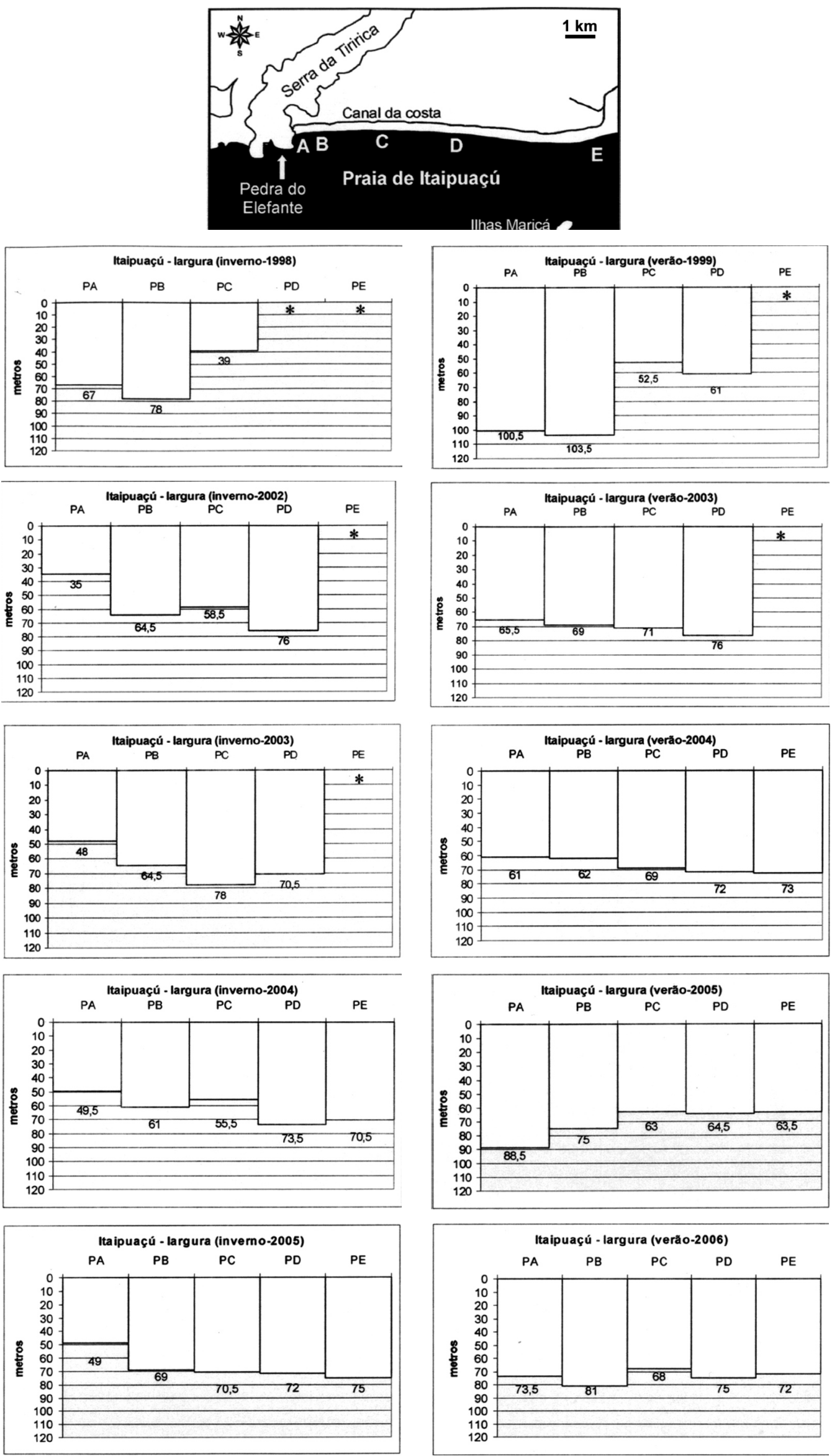

Figura 5 - Gráficos confeccionados a partir dos dados originais de perfis topográficos de praia, com a largura da praia de Itaipuaçú até o nível médio do mar (observado no campo), entre inverno de 1998 e verão de 2006. (*) Dados inexistentes. 
Tabela 3 - Dados relativos ao ângulo de inclinação da frente de praia em Itaipuaçú.

\begin{tabular}{l|c|c|c|c|c}
\hline & \multicolumn{5}{c}{ Praia de Itaipuaçú } \\
\hline Verão-1999 & Perfil A & Perfil B & Perfil C & Perfil D & Perfil E \\
\hline Inverno-2002 & $25^{\circ}$ & $25^{\circ}$ & $23^{\circ}$ & $*$ & $*$ \\
\hline Verão-2003 & $35^{\circ}$ & $21^{\circ}$ & $14^{\circ}$ & $19^{\circ}$ & $*$ \\
\hline Inverno-2003 & $22^{\circ}$ & $19^{\circ}$ & $16^{\circ}$ & $15^{\circ}$ & $*$ \\
\hline Verão-2004 & $18^{\circ}$ & $19^{\circ}$ & $19^{\circ}$ & $22^{\circ}$ & $*$ \\
\hline Inverno-2004 & $25^{\circ}$ & $26^{\circ}$ & $21^{\circ}$ & $23^{\circ}$ & $20^{\circ}$ \\
\hline Verão-2005 & $20^{\circ}$ & $27^{\circ}$ & $15^{\circ}$ & $16^{\circ}$ & $16^{\circ}$ \\
\hline Inverno-2005 & $27^{\circ}$ & $17^{\circ}$ & $20^{\circ}$ & $21^{\circ}$ & $18^{\circ}$ \\
\hline Verão-2006 & $40^{\circ}$ & $23^{\circ}$ & $25^{\circ}$ & $22^{\circ}$ & $17^{\circ}$ \\
\hline
\end{tabular}

* Sem informação.

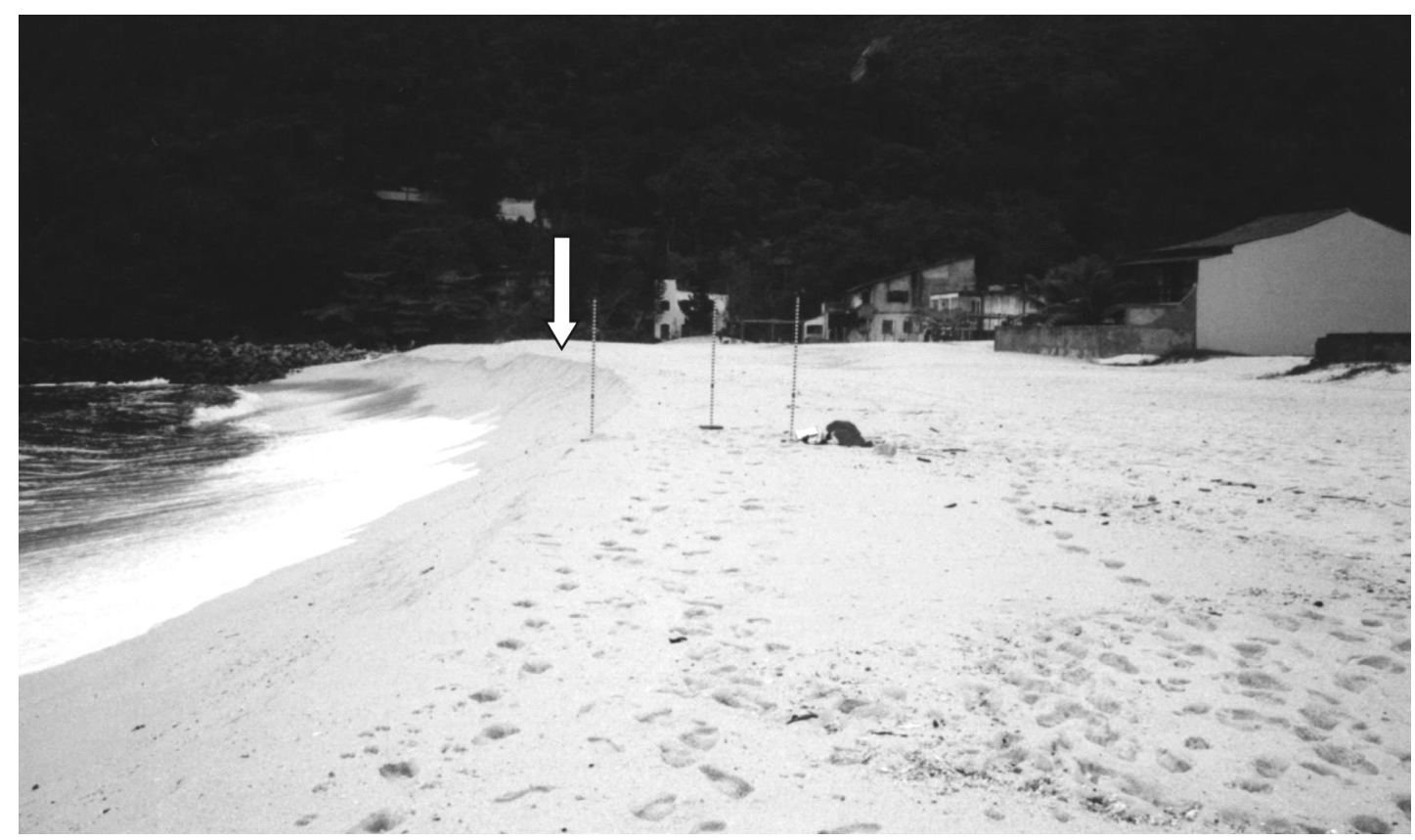

Figura 6 - Extremo oeste da praia de Itaipuaçú no inverno de 2005 apresentando uma escarpa de tempestade (seta) com declividade em torno de $40^{\circ}$.

apontam para o predomínio de areia muito grossa, junto à extremidade oeste (perfis $\mathrm{A}$ e $\mathrm{B}$ ), variando de muito grossa a grossa nas proximidades do meio do arco praial (perfis C e D) e grossa, no pontal de Itaipuaçú (perfil E). Desta forma, evidenciou-se um aumento no tamanho dos grãos em direção a oeste (Tab. 4 e Fig. 10).

Observou-se que há um padrão de selecionamento das areias da praia, no sentido de aumento no grau de selecionamento em direção a leste (Fig. 10) também constatado por Santos \& Silva (2000). Podese constatar também, um maior selecionamento junto 


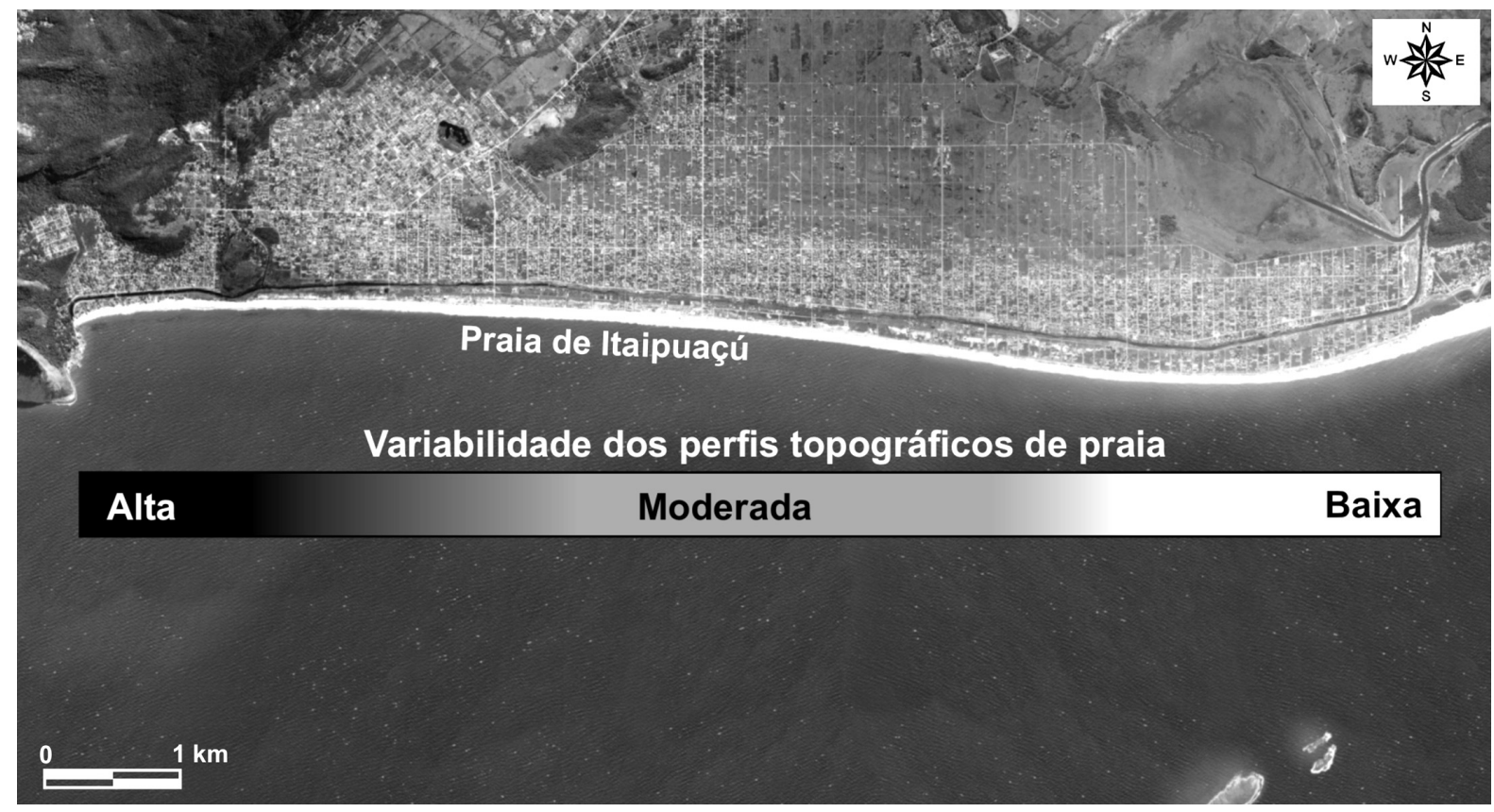

Figura 7 - Mapa de variabilidade morfológica da praia de Itaipuaçú. Imagem Magalhães, M., 2004.

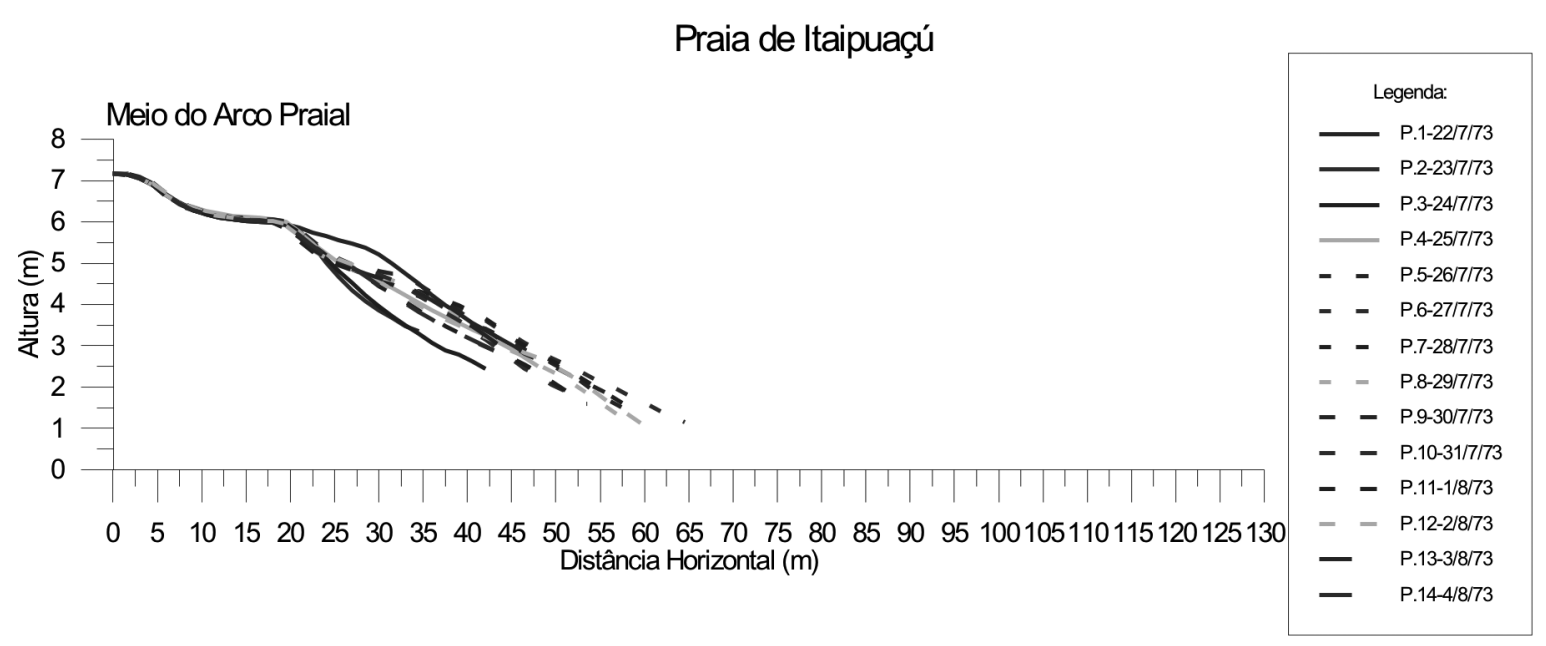

Figura 8 - Perfis topográficos realizados no meio do arco praial de Itaipuaçú no inverno de 1973 (Muehe, 1975).

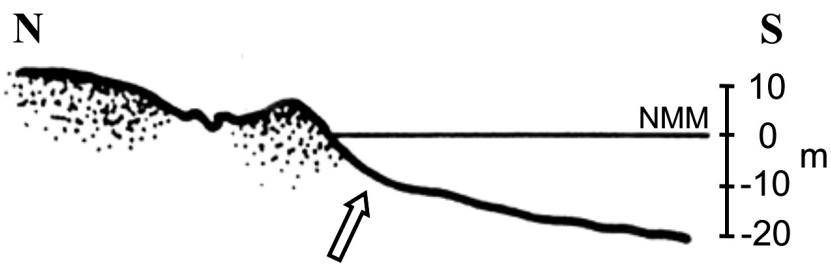

Figura 9 - Perfil topográfico e submarino transversal realizado no meio do arco praial em Itaipuaçú, orientado de norte a sul (Muehe \& Correa, 1989). A seta aponta a área do perfil com elevada concavidade (NMM representa o Nível Médio do Mar). à frente de praia em relação ao pós-praia, o que é um comportamento compatível com a dinâmica de frente de praia.

O comportamento sedimentar diferenciado da praia de Itaipuaçú ao longo do arco praial com sedimentos mais grossos no setor oeste e um melhor selecionamento no setor leste (Fig. 10), resulta da interação de diversas variáveis, tais como: a maior dinâmica no extremo oeste da praia, resultando em um maior percentual de grossos neste trecho; a influência de correntes de deriva litorânea, o que ocasiona um melhor selecionamento das areias a leste; e o papel mitigador das ilhas de Maricá junto ao extremo leste da praia, contri- 
Tabela 4 - Resultado da análise granulométrica das amostras coletadas na Praia de Itaipuaçú segundo a classificação de Wentworth (1922), em: Pettijohn (1975).

\begin{tabular}{|c|c|c|c|c|c|c|}
\hline \multicolumn{7}{|c|}{ Praia de Itaipuaçú } \\
\hline & & Perfil A & Perfil B & Perfil C & Perfil D & Perfil E \\
\hline \multirow{2}{*}{ 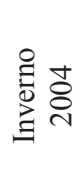 } & Frente de praia & $\begin{array}{l}\text { Areia muito } \\
\text { grossa }\end{array}$ & $\begin{array}{l}\text { Areia muito } \\
\text { grossa }\end{array}$ & Areia grossa & $\begin{array}{l}\text { Areia muito } \\
\text { grossa }\end{array}$ & Areia grossa \\
\hline & Pós-praia & $\begin{array}{l}\text { Areia muito } \\
\text { grossa }\end{array}$ & $\begin{array}{c}\text { Areia muito } \\
\text { grossa }\end{array}$ & $\begin{array}{c}\text { Areia muito } \\
\text { grossa }\end{array}$ & Areia grossa & Areia grossa \\
\hline \multirow{2}{*}{ 赵苛 } & Frente de praia & $\begin{array}{l}\text { Areia muito } \\
\text { grossa }\end{array}$ & $\begin{array}{l}\text { Areia muito } \\
\text { grossa }\end{array}$ & $\begin{array}{l}\text { Areia muito } \\
\text { grossa }\end{array}$ & $\begin{array}{l}\text { Areia muito } \\
\text { grossa }\end{array}$ & Areia grossa \\
\hline & Pós-praia & $\begin{array}{l}\text { Areia muito } \\
\text { grossa }\end{array}$ & $\begin{array}{l}\text { Areia muito } \\
\text { grossa }\end{array}$ & Areia grossa & Areia grossa & Areia grossa \\
\hline \multirow{2}{*}{ 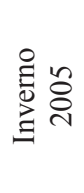 } & Frente de praia & $\begin{array}{l}\text { Areia muito } \\
\text { grossa }\end{array}$ & $\begin{array}{l}\text { Areia muito } \\
\text { grossa }\end{array}$ & $\begin{array}{l}\text { Areia muito } \\
\text { grossa }\end{array}$ & Areia grossa & Areia grossa \\
\hline & Pós-praia & $\begin{array}{l}\text { Areia muito } \\
\text { grossa }\end{array}$ & $\begin{array}{l}\text { Areia muito } \\
\text { grossa }\end{array}$ & $\begin{array}{l}\text { Cascalho muito } \\
\text { fino }\end{array}$ & $\begin{array}{l}\text { Areia muito } \\
\text { grossa }\end{array}$ & Areia grossa \\
\hline \multirow{2}{*}{ 㺃 } & Frente de praia & $\begin{array}{l}\text { Areia muito } \\
\text { grossa }\end{array}$ & $\begin{array}{l}\text { Areia muito } \\
\text { grossa }\end{array}$ & Areia grossa & Areia grossa & Areia grossa \\
\hline & Pós-praia & $\begin{array}{l}\text { Areia muito } \\
\text { grossa }\end{array}$ & $\begin{array}{l}\text { Areia muito } \\
\text { grossa }\end{array}$ & $\begin{array}{l}\text { Areia muito } \\
\text { grossa }\end{array}$ & Areia grossa & Areia grossa \\
\hline
\end{tabular}

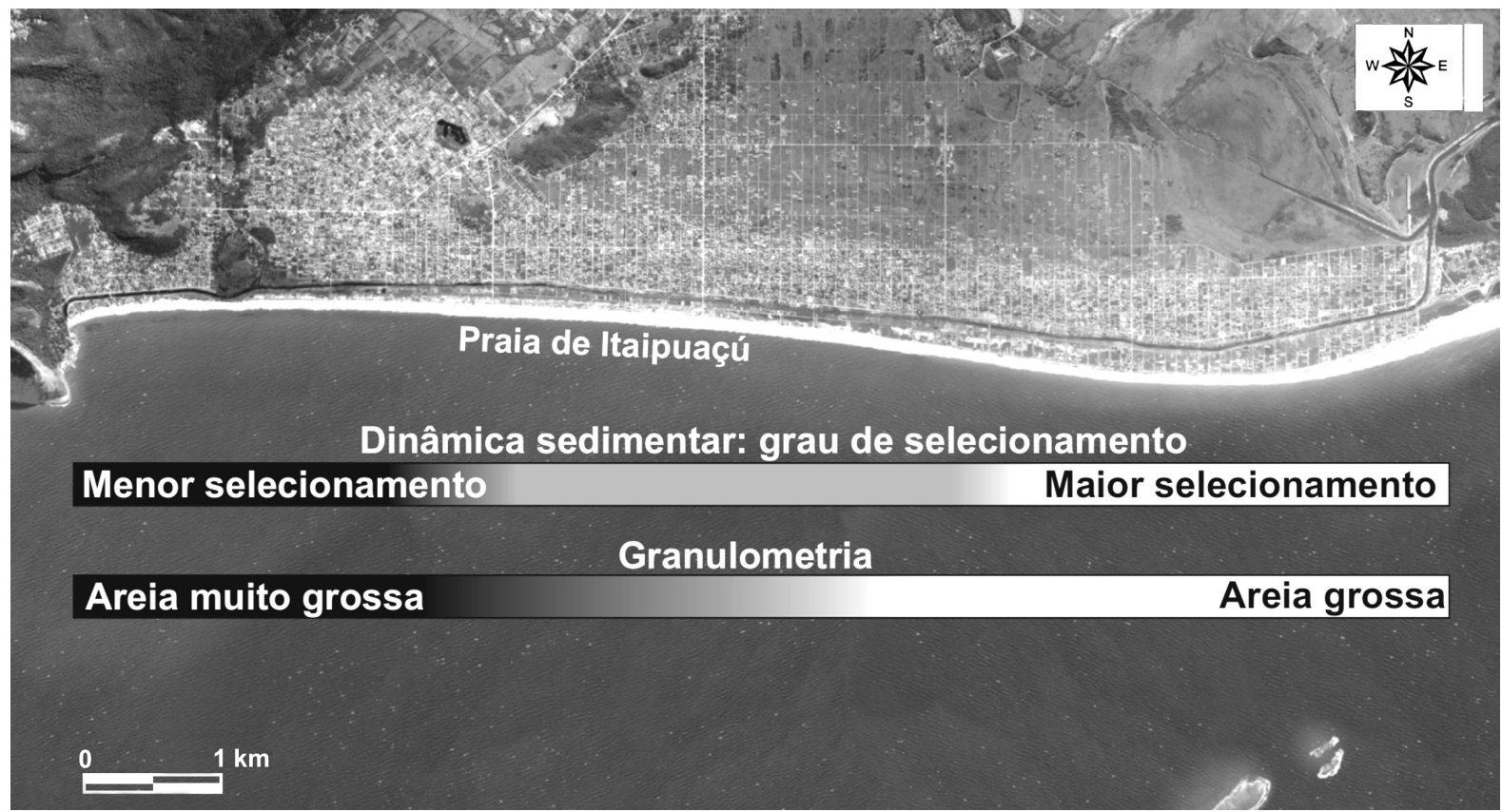

Figura 10 - Mapa de caracterização sedimentar da praia de Itaipuaçú. Imagem Magalhães, M., 2004.

buindo para que as ondas incidam com menor energia no extremo leste da praia.

CONSIDERAÇÕES FINAIS Os resultados permitem constatar que: (1) A praia de Itaipuaçú apresenta um caráter altamente dinâmico, o qual responde às variações nas condições hidrodinâmicas estreitando-se e alargando-se significativamente e rapidamente. O setor oeste do arco praial, em especial, é o mais dinâmico e de maior susceptibilidade a ação de ondas de ressacas. (2) A dinâmica sedimentar é caracterizada pela grande mobilidade de sedimentos ao longo da praia em resposta a ação das correntes de deriva litorânea e entre a parte emersa 
e submersa da mesma em resposta as ressacas. Observa-se uma variação importante no tamanho dos grãos e no grau de selecionamento, com aumento da granulometria e diminuição do grau de selecionamento em direção a oeste. (3) A praia não apresenta tendência característica de erosão: a comparação de perfis topográficos de praia coletados ao longo de 3 décadas, com a mesma metodologia, não aponta para uma diminuição na largura da praia, que apresentou variação entre 35 e 100 metros aproximadamente. No entanto, o perfil da "shoreface" (Muehe \& Corrêa 1989) é extremamente íngreme, sugerindo intensa remoção de areias em lâmina d'água de até 10 metros. Sendo assim, a dinâmica apresentada pela praia de Itaipuaçú não apresenta tendência erosiva, pois a mesma, quando se estreita em decorrência das ressacas, é suprida por sedimentos oriundos da "shoreface", que apesar de escarpada, ainda consegue contribuir para a recuperação da praia. Resta saber, até quando tal processo continuará ocorrendo, principalmente porque a parte oeste da barreira arenosa retrogradou cerca de cerca de 13 metros no período de 28 anos, levando-se em consideração a posição da crista da restinga entre 1976 e 2004 (Silva et al. 2005, Silva 2006).
Desta forma, conclui-se que a praia de Itaipuaçú, apesar de não apresentar comportamento erosivo, é uma praia com dinâmica elevada, podendo se estreitar consideravelmente com as ressacas. Em função do rápido processo de urbanização que vem ocorrendo neste trecho do litoral, nem sempre se respeitando a dinâmica característica deste ambiente, como pode ser constatado com a construção de obras de engenharia dentro dos limites da praia e a conseqüente destruição das mesmas, e a retirada de areia da área litorânea, considera-se preocupante a situação dessa região. Esta situação reforça a necessidade de realização de estudos prévios (muitas vezes de médio e longo prazo) para a construção de obras de tal porte, sobretudo em se tratando de ambientes dinâmicos, como é o caso.

Agradecimentos O presente estudo integra resultados obtidos ao longo de vários projetos desenvolvidos junto ao Departamento de Geologia/UFF que permitiu a elaboração de dissertações de mestrado, monografia e projetos voltados para o entendimento da dinâmica do litoral de Itaipuaçú. Agradecimentos a CAPES e FAPERJ pela concessão das bolsas de mestrado e apoio técnico.

\section{Referências}

Emery K.O. 1961. A Simple Method of Measuring Beach Profiles. Limnology and Oceanographic, 6:90-93.

Muehe D.C.E.H. 1975. Análise Ambiental no Sistema Costeiro Sul-oriental do Estado do Rio de Janeiro. Dissertação de Mestrado, Pós Graduação em Geografia da Universidade Federal do Rio de Janeiro, p. 141.

Muehe D.C.E.H. 1984. Evidências de recuo dos cordões litorâneos em direção ao continente no litoral do Rio de Janeiro. In: Lacerda L.D., Araújo D.S.D. de, Cerqueira R., Turcq B. (eds.) Restingas: origem, estruturas e processos. CEUFF, Simpósio sobre Restingas Brasileiras, atas, Universidade Federal Fluminense, p. 75-80.

Muehe D.C.E.H. \& Corrêa C.H.T. 1989. The Coastline Between Rio de Janeiro and Cabo Frio. Coastlines of Brazil. American Society of Civil Engineers. New York, US, p. $110-123$.

Muehe D.C.E.H. 1994. Geomorfologia Costeira. In: Guerra A.J.T. \& Cunha S.B. (eds.) Geomorfologia Uma Atualização de Bases e Conceitos. Rio de Janeiro, Bertrand Brasil, p. 253-308.

Pettijohn F.J. 1975. Sedimentary Rocks. Third Edition. New York, , Harper and Row Publishers, 628p.

Santos R.H.M \& Silva M.A.M. 2000. Morfodinâmica e Sedimentologia da Praia de Itaipuaçú. In: Universidade do Vale do Itajaí, $1^{\circ}$ Simpósio Brasileiro sobre Praias Arenosas, Itajaí, SC, atas, p. 73-74.
Santos C.L. dos, Silva M.A.M. da, Salvador M.V. S. 2005. Dinâmica Sazonal e os Efeitos das Ressacas nas Praias de Niterói/RJ. Revista Brasileira de Geociências, 34(3):355-360.

Silva A.L.C., Silva M.A.M., Ribeiro G.P., Santos R.A., Vasconcelos S.C. 2005. Os Leques de Arrombamento e a Retrogradação da Barreira Arenosa da Parte Oeste da Praia de Itaipuaçú, Marica/RJ. In: SBG, Simpósio de Geologia do Sudeste, 9, Niterói, RJ, atas, p. 187.

Silva A.L.C. 2006. Comportamento Morfológico e Sedimentológico do Litoral de Itaipuaçú (Marica) e Piratininga (Niterói), RJ, nas últimas três décadas. Dissertação de Mestrado, Universidade Federal Fluminense, 153p.

Silva A.L.C., Silva M.A.M., Santos C.L. 2006. Comportamento Morfodinâmico das Praias de Itaipuaçú (Maricá) e Piratininga (Niterói), RJ, nas últimas três décadas. In: Congresso Brasileiro de Geologia, 43, Aracajú, SE, anais, p. 216.

Silva M.A.M., Resende M.C.C. M., Santos C.L. 1999. Um Estudo sobre a Dinâmica das Praias de Niterói (Baía de Guanabara, RJ). Anais da Academia Brasileira de Ciências, 71(4):962-967.

Manuscrito ID 9597

Submetido em 22 de outubro de 2007 Aceito em 10 de junho de 2008 Sistema eletrônico de submissão 